\title{
India to envision One Health movement for confronting emerging health threats: From concept to approach toward institutionalization
}

\author{
Prejit NambiariD \\ Centre for One Health Education, Advocacy, Research and Training (COHEART), KVASU, Pookode, Wayanad, Kerala, \\ India. \\ Corresponding author: Prejit Nambiar, e-mail: prejit@kvasu.ac.in \\ Received: 24-07-2020, Accepted: 10-10-2020, Published online: 02-12-2020
}

doi: www.doi.org/10.14202/IJOH.2020.165-176 How to cite this article: Nambiar P (2020) India to envision One Health movement for confronting emerging health threats: From concept to approach toward institutionalization, Int. J. One Health, 6(2): 165-176.

\begin{abstract}
The author's key role in advocating and leading One Health $(\mathrm{OH})$ initiatives in India (especially in Kerala), review the need for and progress of $\mathrm{OH}$ from concept to approach and proposes its institutionalization as the way forward. India is currently facing many health threats such as antimicrobial resistance, environmental health hazards, and food safety risks and most importantly, zoonotic diseases such as Nipah, Avian Influenza, Scrub typhus, Congo fever, Kyasanur forest disease, COVID-19, and leptospirosis that grossly impact country's economy. The recent pandemics had exposed the gaps in public health policy and government is prepared to commit on the $\mathrm{OH}$ approach and to invest more on public health infrastructure. Further, as challenges have increased in recent years, $\mathrm{OH}$ approach was clearly advocated by the experts not only to cope up the pandemic but also to manage the infodemic by promoting the timely dissemination of accurate information. Right from the endorsement of $\mathrm{OH}$ in 2007 by India's Prime minister to the present fight against COVID-19 pandemic, the actions to control and manage the disease was ideally oriented toward a collaborative approach. Last year (2019), the representatives from relevant ministries and department had a ground-breaking dialog to develop charter and constitute a National policy on OH. Recently, Health Ministers of the Member States of the World Health Organization South-East Asia signed "Delhi declaration" where the key essence was to implement intersectoral coordination mechanisms following the "OH" approach. India's future policy intervention will emphasize on strengthening of integrated public health labs and contributing to building a national institutional platform for $\mathrm{OH}$ to boost research initiatives. Taking stock of $\mathrm{OH}$ happenings, resources, challenges, and priorities, the implementation strategy has been proposed across human, animal and environmental health. The article further highlights the key areas that need $\mathrm{OH}$ intervention in India, the country's progress in $\mathrm{OH}$ and the success stories of $\mathrm{OH}$ for a sustainable action to confront emerging health threats.
\end{abstract}

Keywords: collaboration, emerging zoonoses, health threats, India, One Health (OH) - Approach, OH-Concept, $\mathrm{OH}-$ Initiative, OH- Institutionalization.

\section{Introduction}

"One Health $(\mathrm{OH})$ is a validated, integrated, and holistic approach that is being advocated by the World Health Organization (WHO), the Food and Agriculture Organization (FAO) of the United Nations, and the World Organization for Animal Health (OIE) for combating health threats to humans and animals through human-animal-plant-environment interface" [1]. The idea of the $\mathrm{OH}$ concept is, in essence, to appreciate the wealth of opportunity that lies in the three interfaces, namely, human, animal, and environment, which could be capitalized on, to protect the health of our planet as a whole [2]. The necessity of a coordinated, collaborative, multi-disciplinary, and cross-sectorial approach to address potential health risk paved the way for "OH" thinking in India [3]. A lack of interdisciplinary collaboration and "working in silos" attitude

Copyright: Nambiar. This article is an open access article distributed under the terms of the Creative Commons Attribution 4.0 International License (http://creativecommons.org/licenses/ by/4.0/), which permits unrestricted use, distribution, and reproduction in any medium, provided you give appropriate credit to the original author(s) and the source, provide a link to the Creative Commons license, and indicate if changes were made. The Creative Commons Public Domain Dedication waiver (http:// creativecommons.org/ publicdomain/zero/1.0/) applies to the data made available in this article, unless otherwise stated. has resulted in many zoonotic diseases establishing its hub and causing endemicity in several parts of India. This has the potential to cause huge economic crises such as the present COVID 19 pandemic. Thus, there is a need to advance $\mathrm{OH}$ by developing a framework and policy for India based on sustainable development. India is currently facing several zoonotic disease threats due to the exponential growth in human and livestock population, rapid urbanization, rapidly changing farming systems, closer interaction between livestock and wildlife, forest encroachment, changes in ecosystems, and globalization of trade of animal products [4]. An estimate indicates that around 1.67 million viruses are enzootic, with up to $50 \%$ of these having the potential to invade humans [5]. The complexities of health threats demand cross-disciplinary strategies and to inculcate these habits, several capacity-building programs on $\mathrm{OH}$ concept were held in India $[2,6,7]$. Many scientific experts express that India must have an $\mathrm{OH}$ policy for a cogent response [8,9]. Now, we are in a phase that ministries plans to consider $\mathrm{OH}$ as a next generation movement for addressing pandemic threats. Southern state, like Kerala has a long history of organized health-care [10], with several $\mathrm{OH}$ success stories [11]. 
India thus requires strong and resilient public health systems to address threats that exist at the human-animal-environment interface. An $\mathrm{OH}$ approach has proven to counter such threats. This article reviews the country's $\mathrm{OH}$ initiatives, its progress from concept to approach and the key areas that call for $\mathrm{OH}$ intervention. The article also proposes the way forward to institutionalize $\mathrm{OH}$, both at state and national (India) level, in order to mitigate the impact of catastrophic events that may occur both in humans and animals, thus safeguarding the health of the planet.

\section{Urgent Areas that Call for OH Attention in India}

India is the fastest-growing country in the world. The factors that make India a hotspot for disease threat includes its large surface area $\left(32,87,263 \mathrm{~km}^{2}\right)$ that accounts for $2.4 \%$ of the total world area along with enormous population size of approximately $17 \%$ of world's population and rich variety of fauna. Further, India shares border with seven countries and is heavily forested with a total forest cover of $708,273 \mathrm{~km}^{2}$, which is $21.54 \%$ of the total area of the country [12]. Thus, the health-care sector is coming under increasing pressure calling for urgent $\mathrm{OH}$ attention. The areas where $\mathrm{OH}$ approach can be ideal are detailed below.

\section{Zoonotic and emerging infectious diseases (EID)}

The global $\mathrm{OH}$ movement has become firmly entrenched in both political and scientific discourse pertaining to zoonotic and EID's in the past decade [13]. A comprehensive study has revealed that $75 \%$ of the EID's seen in human populations are of animal origin especially from the wild [14]. Habitat destruction, rampant deforestation, and man-made changes in the landscape have created a "perfect storm" for the spillover of diseases from wildlife to people. World over, scientists have identified India as a major Global Disease Hotspot [15]. Following the "bird flu" pandemic in 2007, several other emerging zoonotic diseases scared the nation such as Nipah virus (NiV), Kyasanur forest disease (KFD), Zika Virus, Japanese encephalitis, West Nile Virus [16], and the latest COVID 19 pandemic [17] which all are quintessential $\mathrm{OH}$ pathogens. While there is some level of success today in disease surveillance programs, individually at the human level through integrated disease surveillance program (IDSP) and animal level through National Animal Disease Reporting System (NADRS), such systems fall short in tracking the chain of transmission at the interface of zoonosis [2].

\section{Antimicrobial resistance (AMR)}

AMR is a complex, multifaceted problem that threatens human and animal health, the global economy, and national and global security that demands integrated and holistic multisectoral $\mathrm{OH}$ approach [18]. The rates of AMR have been rising disproportionately in the past few decades [19]. With 700,000 people losing battle to AMR per year and another 10 million projected to die from it by 2050 , AMR alone is killing more people than cancer and road traffic accidents combined together [20]. India holds the fourth position in the world when it comes to antibiotic consumption by food animals, accounting for 3\% of the global consumption [21]. The India's National Action Plan (NAP) against AMR marks a significant step in terms of government's convergent effort to tackle AMR issues [2].

\section{Food safety hazards}

Adoption of an integrated approach to food safety throughout the food chain "from farm to fork" is critical to prevent foodborne diseases and other food safety hazards [22]. Foodborne illness and food safety issues constitute an unmanageable enigma in India with varied food habits. Unmonitored social functions, fast foods, reuse of stored food and inadequate knowledge about food poisoning, are some of the common factors leading to such food poisoning episodes [4]. With the implementation of Food Safety and Standards Act, 2006, India was able to lay down science based standards for articles of food to ensure availability of safe and wholesome food for human consumption. The areas for $\mathrm{OH}$ intervention for preventing food safety hazards include outbreak investigation of foodborne illness, laboratory network for pathogen identification, joint research and surveillance of foodborne pathogen, by improving animal health to help minimize food contamination by infectious pathogens, training, and demonstration programs on food safety measures [4].

\section{Environmental health hazards}

The climate induced changes are adversely affecting the livelihood options of the people and animals of India. The field of climate change represents an excellent opportunity for researchers to work across disciplines to integrate diverse data sources, develop cross-cutting methodologies, and answer questions about the broader effects of environmental health on human health and animal welfare [23]. Similarly, collaborative action is required for the management of air or water pollution and waste management. Marine ecosystem is being threatened by the discharge of untreated sewage wastes and industrial effluents which ultimately affects the sustainability of living resources and public health [24]. The control of vector-borne disease cannot be addressed without consideration of the impact of natural and man-made environmental changes on patterns of disease vector proliferation [23]. Thus, with regard to climate change perspective and its impact on man or animals, there is an urgent necessity of $\mathrm{OH}$ approach where the environmental health sectors can contribute the maximum [25].

\section{Genesis of $\mathrm{OH}$ Concept in India}

India first recognized $\mathrm{OH}$ concept to respond to Avian Influenza (H5N1) pandemic. During December 
4-6, 2007, the International Ministerial Conference on Avian and Pandemic Influenza was held at New Delhi India. The conference was organized and hosted by the Government of India with cooperation of various International Organizations, namely, WHO, FAO, OIE, World Bank, and UNICEF. Representatives of 111 countries participated. During this meeting, the then Indian Prime minister said that the Government of India supports the concept of "OH" based on an integrated approach to animal and human health [26]. It was declared in the meeting that promoting $\mathrm{OH}$ could be the natural extension of the Global Response to H5N1.

Although the genesis of $\mathrm{OH}$ ideology began in 2007, India has sown the seeds in the year 2005 when its action plan for preparedness, control, and containment of H5N1 developed by the Department of Animal Husbandry, Dairying and Fisheries [27] and the contingency plan for the management of human cases of H5N1 developed by Directorate General of Health Services [28] was ready in the year 2005, much before the first H5N1 was reported in February, 2006 [29]. This clearly shows that India's wheels of $\mathrm{OH}$ started rolling in the year 2005, just a year after the current global $\mathrm{OH}$ movement that was ignited by the Manhattan Principles 2004 [30].

\section{India's Key OH Initiatives}

The key happenings in the $\mathrm{OH}$ movement (subsequent to $\mathrm{H} 5 \mathrm{~N} 1$ preparedness) portrays that India is geared up for a paradigm shift to expand interdisciplinary collaborations and communications in all aspects of health-care for humans and animals.

\section{9: India joined with OH network of South Asia (OHASA)}

OHASA was launched by the Wildlife Trust to form a cohesive regional network of scientists and policymakers from Ministries of Health, Agriculture and Environment, as well as Nongovernmental Organizations and universities in India, Bangladesh, Pakistan, and Nepal to address zoonotic diseases [31].

2010: In-country OH collaborations (Centre for Disease Control and Prevention [CDC] and National Centre for Disease Control [NCDC])

Recognizing the need to broaden cooperation on health, especially emerging global diseases between India and USA, a Global Disease Detection - India Centre has been established in NCDC. This is a joint collaboration between the Ministry of Health and Family Welfare (MOHFW), Government of India that are represented by NCDC and the US Department of Health and Human Service, CDC. NCDC also runs a program called intersectoral Coordination for Prevention and Control of Zoonotic Diseases that helps to strengthen co-ordination between Medical, Veterinary, wildlife sector, and various relevant stakeholders [32].

2014: India launched new $\mathrm{OH}$ center and $\mathrm{OH}$ course

Kerala Veterinary and Animal Science University established a Centre for OH Education, Advocacy,
Research and Training (COHEART) on February 26, 2014, and also launched two new course in $\mathrm{OH}$, namely, PG Diploma in $\mathrm{OH}$ and PG Certificate in $\mathrm{OH}$ Surveillance $[33,34]$. The university is stepping forward to launch a $\mathrm{PhD}$ program in $\mathrm{OH}$ looking at the demand to build a new cadre of $\mathrm{OH}$ professionals to fight pandemics. The economics of $\mathrm{OH}$ approach is given due importance in all the courses.

\section{5: Employment Initiative to recruit cross-sec- toral professional \\ The recruitment of a veterinarian at the IDSP State Surveillance Unit in each of the states of India served as a bridge between the two sectors [9]. There is also veterinary consultant being recruited by Directorate of Public Health of different State Governments.}

\section{6: $\mathrm{OH}$ concept introduced in veterinary curriculum}

In exercise of the powers conferred by Indian Veterinary Council Act, 1984, the Veterinary Council of India has included for the first time $\mathrm{OH}$ concept in B.V.Sc. curriculum and is covered under Unit $1-$ Veterinary Public Health and food safety [35]. Similar initiatives were made to include $\mathrm{OH}$ in M.V.Sc. curriculum.

\section{7: India's NAP-AMR incorporated OH approach}

MOHFW notified three governance mechanisms in September 2016 to address AMR challenge with help, of which has drafted the NAP-AMR that has incorporated the $\mathrm{OH}$ approach [36].

\section{8: The launch of IDSP's Integrated Health Information Platform}

The union health secretary launched IDSP's Integrated Health Information Platform on November 26, 2018, which is new state-of-the art Information Platform to monitor public health surveillance.. The path-breaking initiative will provide near-real-time data to policymakers for detecting outbreaks, reducing morbidity and mortality, and lessening disease burden in the populations and better health systems. The first one-of-its-kind initiative by the Government of India, IHIP uses the latest technologies and digital health initiatives [37].

\section{9: OH India declaration}

During the conference held at New Delhi, decision was taken by the scientific community to launch India's $\mathrm{OH}$ Initiative to tackle the most urgent health threats and has also proposed $\mathrm{OH}$ roadmap for India. The conference was hosted by the Department of Biotechnology (DBT), Ministry of Science and Technology in partnership with Ministry of Agriculture and Farmers' Welfare and MOHFW and their respective departments [38].

2019: Delhi declaration-signed by Health Minister of India and other Member States advocates the "OH" approach

Health Ministers of the Member States of the WHO South-East Asia Region participated in the Seventy-second Session "Emergency Preparedness 
in the South-East Asia Region" at the WHO Regional Committee for South-East Asia in New Delhi, India. The deliberation brought about "Delhi Declaration" on September 03, 2019 that was aimed to develop, support, and implement intersectoral coordination mechanisms following the "OH" approach [39].

\section{0: Launch of $\mathrm{OH}$ Centre in Maharashtra}

The $\mathrm{OH}$ center was initiated through collaboration with Maharashtra Animal and Fishery Sciences University and Indian Council of Medical Research (ICMR)-National Institute of Virology, Pune [40].

\section{0: Proposed National Institutional Platform for $\mathrm{OH}$}

The central government while announcing recovery plans for COVID-19 crisis under Atma Nirbhar Bharat economic stimulus package mentioned that ICMR will be contributing to building a national institutional platform for $\mathrm{OH}$ that will boost research initiatives [41].

\section{0: National expert group on $\mathrm{OH}$}

On May 14, 2020, a National expert group on $\mathrm{OH}$ was constituted and terms of reference (ToR) were defined by DBT to promote multisectoral, transdisciplinary collaboration, and cooperation to achieve $\mathrm{OH}$ framework in India [42].

\section{Building Evidence Base for $\mathrm{OH}$ India Movement}

In India, there are many initiatives that depict growing evidence of $\mathrm{OH}$ approach [43-45]. Tamil Nadu had successfully implemented a state-wide, multisectoral rabies control initiative that included public health surveillance, animal census, dog licensing rules, waste management, animal birth control, anti-rabies vaccination, and awareness campaigns [43]. There are several examples that have adopted $\mathrm{OH}$ practices $[44,45]$; however, the article limits to the success stories reported in Kerala alone for building the evidence. The major $\mathrm{OH}$ effort in Kerala was the launch of Kerala Antimicrobial Resistance Strategic Action Plan (KARSAP), formulated on the principles of $\mathrm{OH}$. Kerala was first state in India to come up with a state level action plan with technical support from WHO country office in India. The other $\mathrm{OH}$ actions in Kerala are detailed here.

\section{Kerala's fight against KFD}

Health authorities communicated to veterinary authorities about confirmed case of KFD in Wayanad in the year 2015. A forest guard who had disposed of the monkey carcass had succumbed to the disease and reported the history of observing a dead monkey. Spot surveillance of the area by health department revealed more fever cases among women working as fire line workers [46]. The Human Health Sector conducted fever surveillance, vaccination (ensuring that all risk groups are vaccinated), designing treatment protocols, inpatient care and expert treatment, sample collection for diagnosis, liaison building with laboratories for prompt result communications, close surveillance to rule out relapsing, create disease awareness, insecticide dusting at monkey death areas, lead and coordinate activities with other relevant departments, and daily/weekly reporting the disease status to district administrator. The Animal Health Sector created disease awareness, postmortem of monkey carcass, identification of tick vectors, epidemiological surveillance, and vector control activities in domestic animals [26]. The forest department reported cases of monkey deaths; referral laboratories for diagnosis. Tribal development department distributed compensation for the bereaved families; media helped in spreading awareness messages and police for law and order.

\section{Kerala's fight against H5N1}

Veterinary authorities communicated to health authorities about confirmed case of H5N1 outbreak in Central Kerala in November 2014 and 0.26 million ducks were culled. Another outbreak was reported on January 25, 2015 at Regional Poultry Farm, Kureepuzha in district Kollam of Kerala [47]. The $\mathrm{H} 5 \mathrm{~N} 1$ strain of virus is pandemic and contagious to human beings. The outbreak also had its impact on the broiler sector and its consumption has drastically reduced in Kerala. Ancillary industries were also hit due to this outbreak. The Animal Health Sector coordinated with other relevant departments for swift action to cull all chickens, ducks, and other domestic birds in and around $1 \mathrm{~km}$ radius of epicenter, droppings, feed and other materials of the birds were also destroyed, 24-h control rooms were set up, distributed protective clothing to public in the affected areas, conducting awareness camps, monitoring of the dead birds in water bodies and dead birds lying unnoticed in the fields, surveillance around $10 \mathrm{~km}$ of the areas from where the mass death of birds had been reported, and surveillance in all other districts of Kerala with special importance to places where migratory birds are present and research on migratory birds. The Human Health Sector undertook prophylaxis of risk groups, regular health check-up of the poultry farmers, biosecurity measures, personal protective equipment's supply, and disease awareness. The forest department promptly reported any unusual deaths among migratory birds, facilitated in conducting the postmortem examination of wild birds; laboratories in diagnosing the disease; media for updating the status of bird flu and spreading awareness and alert to inform about risks and prevention measures; food safety department provided information advisories on safety of poultry products; and police for law and order during crisis.

\section{Kerala's fight against Niv}

During May 2-29, 2018, $23 \mathrm{NiV}$ cases were identified in Kerala, including the index case, of which 18 were laboratory confirmed. The lineage of the NiV responsible for this outbreak was closer to the Bangladesh lineage. This is the first recorded NiV outbreak in South India [48]. The Human Health Sector 
coordinated action with other relevant departments, made prompt diagnosis, treatment, and prophylaxis of affected or prone individuals, ensured prompt supply of antiviral drug, conducted regular check-up of the risk-prone people, organized training on infection control measures, and adequate supply of personal protection equipment was ensured, public health personnel's looked into the biosecurity measures, an advisory (Nipah cell) was formed under direction of Directorate of Health Services and was managed by District Administrator, strengthened hospital infection control activities, barrier nursing enforced, health-care providers instructed to strictly implement biosafety precautions, and disposal of the infected materials strictly monitored and enforced. The Animal Health Sector addressed farm biosecurity measures, helped to source track spillover from bats, involved in collaborative investigation, kept vigilant track on health of domestic animals such as pigs in and around the Nipah infected premises, laboratory liaisoning, Conducting Nipah awareness campaign and providing advisory services. Referral laboratories played a prominent role in diagnosis. Forest Department's role was Sampling Fruit bats of Pteropus sp.; Media's role was to update the status; Police role was to enforce law and order during crisis.

\section{OH Response (Kerala Model)}

The Kerala's $\mathrm{OH}$ response model is solution-based approach that is directed toward specific threats and for overcoming outbreak scenarios. The model is based on observation made by the author and could be described as $7 \mathrm{C}$ process, namely, (1) communication between stakeholders, (2) cooperation protocol for joint action, (3) collective action with district administrator as the head, (4) collaboration and coordination efforts by human, animal, and other allied sectors, (5) continual reporting, (6) critical reviewing, and (7) crisis control and future actions. All 7 C's involve human health, animal health, and environmental health sectors under the leadership of district administrator.

Communication of case/events between stakeholders

Communication within stakeholders is the first stage in $\mathrm{OH}$ action. If the human health sector identifies a threat, for example, an unknown illness in village $\mathrm{X}$ situated near forest hamlets that have a history of few monkey deaths, the animal health sector will be communicated about the case and shall be requested to visit the premises to check for zoonotic linkages with regard to wildlife or other animals. Both, the human health and the animal health sectors visit some of the hot spots, collect samples, and get it tested in the designated laboratory. They then discuss the results to overrule infections. Similarly, if the animal health sector identifies a threat, for example, influenza such as illness in a live bird market, then the human health sector will be communicated about the situation. Both, the human health and the animal health sectors make a visit to the live bird market, collect samples, and sent to the laboratory and to discuss case to rule of disease like H5N1.

\section{Cooperation protocol for joint action}

Once a threat or index case of a disease has been established in the area, the district administrator is appraised about the situation by the reporting authority (District Health/Veterinary Department). The district administrator promptly convenes a meeting by inviting all the relevant stakeholders to discuss the situation and coming up with joint action plans. This is followed by stakeholder workshop to discuss on the roles of respective department and to develop a cooperation protocol for joint action. Experts are invited from other neighboring regions that have proven experience in addressing such threats. The workshop recommends cooperation protocol of action of various departments. The key stakeholders for $\mathrm{OH}$ approach are given in Table-1.

Table-1: Stakeholders of One Health approach in India.

1. International organizations (WHO, OIE, FAO, etc.) Providing top level leadership on Global Health matters

2. Central and state ministries (government) Providing best amenities and country's/state's highest leadership to facilitate requirement of health services to meet the disease control measures

3. District administrators - Is the front-runner to facilitate activities of the district

4. Central health expert teams - Including ICMR, ICAR, and experts from national institutes. For Health and Safety Advisory Services and Situation monitoring etc.

5. Health department (Including role of IDSP and allied health dept.) - For all matters related to human health in the state. Provides Advisory Services, Patient care and treatment, control operations, developing guidelines, Public Awareness, etc.

6. Animal husbandry department - For all matters related to animal health in the state. Advisory services for livestock farmers, Vigilant Animal care, and management

7. Forest and other allied departments: Role specific to the threats identified

8. Laboratories - National laboratories such as NIV and NIHSAD and other laboratories to facilitate detection of pathogens in man, animals to confirm the outbreak and source tracking

9. Medical colleges, tertiary hospitals, and medical associations - Treatment and care of patients and suspected cases, advisory services, research, social media alertness, etc.

10. Veterinary university, veterinary associations - Expert advices, Farm Biosecurity measures, Awareness classes, Liaison building between various departments, social media alertness, etc.

11. National Institutes, Research Centers, NGO's Setting up long term plans for disease control, epidemiological investigation, outbreak tracking, etc.

12. Miscellaneous such as Pharmaceuticals, Food processing industry, Media and other private sector for human and animal health

$\mathrm{WHO}=$ World Health Organization, $\mathrm{OIE}=$ World Organization for Animal Health, $\mathrm{FAO}=$ Food and Agriculture Organization, ICMR=Indian Council of Medical Research, ICAR=Indian Council of Agricultural Research, IDSP=Integrated Disease Surveillance Program, NIV=National Institute of Virology, NIHSAD $=$ National Institute of High Security Animal Diseases, NGO's=Nongovernmental Organizations 
For example: In the year 2015, when Wayanad district reported increased number of KFD cases, a stakeholder workshop was conducted by COHEART inviting District Medical officer (Health), District Animal Husbandry officer, District Forest officer-North/South, Veterinary University, Tribal Development officer, District police Chief, and others. The workshop developed the protocol of action to be followed by various departments and submitted the same to district administrator.

\section{Collective action with district administrator as the head}

District administrator is the top most leader for handling the crisis situation in the district who identifies nodal officers from each of the acting departments. To facilitate further action, district administrator orders for a functional $24 \times 7$ control room. District administrator in the capacity of Chairman of District Disaster Management Authority, identify the threat as a disaster and will lead the control mission. The office endorses the cooperation protocol prepared during the stakeholder's workshop and issues proceeding in this regard to control the threat.

Note: As per section 30 (2) (iii) read with section 30 (2) (v) empowers the DDMA to issue directions to various departments/local authorities in the district to take such measures so as to ensure prevention/mitigation of the disaster. Section 34 empowers the DDMA to take such measures required to manage any disasters or threatening disaster situation [49].

\section{Collaboration and coordination efforts human health,} animal health, and other allied sectors

Based on the proceeding released by district administrator, collaborative activities of various sectors are implemented. This are broadly categorized as action from human health sector, animal health sector, and other allied sectors (Including Environment related). They undertake sectors specific or co-ordinated activities on routine basis. For example, if any death of monkey is observed in a forest, the environment health sector (forest department) conveys the information to animal health sector (Animal Husbandry Department and Veterinary University), who then performs postmortem. The postmortem samples (if suspected of KFD) will be handed over to Human health sector (Health department. The health department submits the sample to laboratory and communicates the result back to the animal health sector.

\section{Continual Reporting}

Each department works on daily reporting system. The human, animal, and environment health sectors make use Google form app for reporting. This reporting system can also be integrated with different department activities so that the activities can be viewed by all nodal officers in a single window. The use of social media platform such as WhatsApp group will further aid in the process of prompt reporting.

\section{Critical Reviewing}

To monitor the progress, weekly review meeting is convened under the chairmanship of district administrator. In this review, meeting discussion will be made on what are the gaps, difficulties, and current status of the threat and how the threat can be controlled.

\section{Crisis Control and Future Actions}

Once the crisis situation is under control in the region, long-term action plans are sought out based on experience. This includes preparedness plan to prevent the threat occurring in future and also research plan which is generally looked on for research institutes to act.

\section{The next step in OH movement India}

Although India was earliest to imbibe $\mathrm{OH}$ in 2005 , the country is yet to institutionalize OH strategic framework at governance level. Several scientist and policymakers in India have advocated the use of cutting-edge technologies in disease forecasting and $\mathrm{OH}$ action strategy as the best tool to face diseases threats that have the potential to become a pandemic [50]. Confirmed evidence that demonstrates the success of using $\mathrm{OH}$ approach can be used to inform policy decisions that are key to the sustainability of $\mathrm{OH}$ [51]. Although the essence of $\mathrm{OH}$ has been well understood both from veterinary perspective and from human health perspective, the actions are largely limited to few collaborative strategies [52]. Neighboring countries such as Bangladesh has a separate "OH Secretariat," and Bhutan and Nepal are working toward it; India has not made much progress. The strategic framework for effective implementation of $\mathrm{OH}$ incorporates political commitment, policy formulation, sustainable financing, program development, knowledge sharing, institutional collaboration, capacity enhancement, engagement of civil society, and active participation of the communities [1]. In the absence of a cogent policy environment, India's approach to dealing with EID events has been reactive at best and absent, at worst [9]. The country also needs to enhance the budget allocation for human health, animal health and environment sectors to make them robust and more responsive to address challenges of $\mathrm{OH}$ (such as the present COVID-19 pandemic) along with developing a common framework for joint Monitoring and Evaluation of the entire program. Hence, the next step in $\mathrm{OH}$ movement India should be its institutionalization of governance level. The reference document for developing the next step in $\mathrm{OH}$ at National level is the " $\mathrm{OH}$ India Conference Declaration and Statement" that was convened by DBT, Ministry of Science and Technology [38]. Initiation in this line has already begun by constituting National expert group on OH on May 14, 2020 [42]. Similarly, the reference document that could serve for developing $\mathrm{OH}$ implementation at state level came as an output of the workshop on "Envisioning the 
institutionalization of $\mathrm{OH}$ for combating emerging public health threats in Kerala" that was convened by COHEART, Kerala Veterinary, and Animal Sciences
University with support from FAO [53]. The author was a participant in the national level conference and a key organizer for the state level workshop. Based

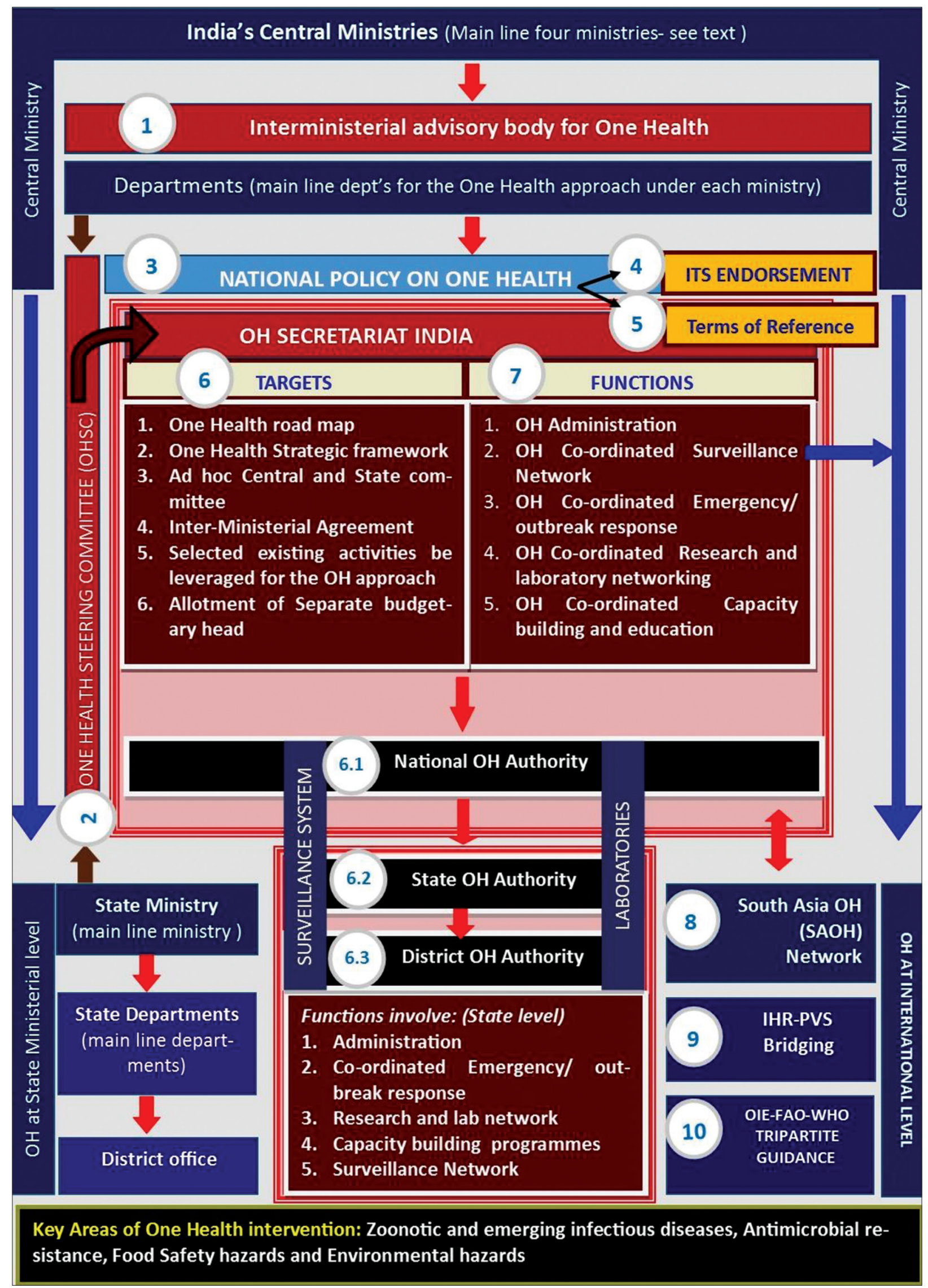

Figure-1: Proposed One Health Governance Guidelines- Mechanism, Structure and Function. 
on the two documents, the following are the suggested way forward and next steps proposed for institutionalizing an $\mathrm{OH}$ platform in India is described in Figure-1.

\section{Constitute an inter-ministerial advisory body for $\mathrm{OH}$}

In India, there are four (or more) main line ministries that can operationalize advocating $\mathrm{OH}$ approaches such as The MOHFW, Ministry of Fisheries, Animal Husbandry and Dairying, and Ministry of Science and Technology and the Ministry of Environment and Forests. Under these ministries, there are departments responsible for implementing $\mathrm{OH}$ related activities. The inter-ministerial $\mathrm{OH}$ advisory body may be formed comprising members from above ministries which will be the key governing body for $\mathrm{OH}$ in India.

\section{Constitute OH Steering Committee (OHSC)}

The steering committee can be constituted comprising representatives from ministries and their Departments, Government Institutions, Bilateral and Multilateral Partners, Civil Society Organizations, the private sector and communities, involved in $\mathrm{OH}$ as that was formulated in countries like Rwanda [54]. Experts from OIE, FAO, WHO, US AID, ILRI, and Connecting Organizations for Regional Disease Surveillance (CORDS) organization can be consulted. The OHSC should provide independent advice to inter-ministerial advisory body. OHSC should involve a multiactors, multi-sectoral, and multi-disciplinary participatory and consensus-building process for the government of India to tackle human, animal, and environmental health-related complex problems.

\section{Draft national policy on $\mathrm{OH}$}

The OHSC members should arrange monthly meetings to develop regulation and National policy on $\mathrm{OH}$ in India. The policy can be designed to establish and foster ownership of the strategy at high levels of the government and in all participating sectors, and to ensure cross-cultural communication across the human and animal domains, research and program divide, and government and nongovernmental divide. The policy can identify priority areas to act using $\mathrm{OH}$ approach, develop a framework as well as define a strategy for sharing disease surveillance data among neighboring countries.

\section{Endorsement of national policy}

Get the policy endorsed by the MOHFW, Ministry of Fisheries, Animal Husbandry and Dairying, Ministry of Science and Technology and the Ministry of Environment and Forests and other participating ministries.

\section{Develop the ToR}

To facilitate the transparent operation of the $\mathrm{OH}$ approach, it is necessary to develop generic ToR. ToR is required for functioning of $\mathrm{OH}$ Secretariat and gets the approval of the inter-ministerial advisory body. The steering committee may meet on a quarterly basis to review progress in the implementation of the strategic plan, discuss challenges, and recommend remedial measures.

\section{Operationalize $\mathrm{OH}$ secretariat: The proposed targets}

\section{At National level}

Once the recommendation to form an $\mathrm{OH}$ secretariat is approved and ToRs are defined, the secretariat can function to monitor and assess the impact of $\mathrm{OH}$ initiatives. A timeline for the action plan to implement an $\mathrm{OH}$ approach should be defined. The secretariat can appoint ad hoc committee to support next implementation process, develop $\mathrm{OH}$ strategic framework, select initial disease project(s) for $\mathrm{OH}$ approach, Draft Inter-Ministerial Agreement, obtain budgetary head and funding for project(s) to be implemented with a $\mathrm{OH}$ approach and functionalize. This process leads to the formation of national $\mathrm{OH}$ authority under the secretariat

\section{At State level}

Efforts need to be made to establish state level and district level $\mathrm{OH}$ committee under State One Health Authority (SOHA) and District One Health Authority (DOHA), respectively, to facilitate, coordinate, review, or monitor $\mathrm{OH}$ related events in the state. The SOHA shall function as the top decision-making body and facilitate, coordinate, review, or monitor all $\mathrm{OH}$ related activities in the state. The DOHA shall act as the district planning, coordinating, and implementing body for health threats and take all measures for the purposes of its management in the district in accordance with the guidelines laid down by the State $\mathrm{OH}$ policy. The district administrator shall act as the Chairman of DOHA. Further activities of state level $\mathrm{OH}$ implementation can be referred to the workshop recommendations [53].

\section{Operationalize OH secretariat: The proposed functions}

\section{Administration (State/Central)}

The administration set up is required to advocate policies on $\mathrm{OH}$ approach and mobilize resources and experts and to coordinate multi-sectoral preparedness and response plans for controlling health threats at human, animal, and environment interface. The administration should foster the exchange of selected data, information, experience, and expertise across sectors. The administration should also develop national and state $\mathrm{OH}$ action plans for prioritized threats and Disease Specific SOPs along with comprehensive plan with clear roles and responsibility of each stakeholder. The Bangladesh $\mathrm{OH}$ functioning follows a rotative leadership between ministries and designated one institute as the $\mathrm{OH}$ Secretariat [55]. The Bangladesh $\mathrm{OH}$ also maintains sectoral independence but establish joint operations for $\mathrm{OH}$ approach [55] which could be ideal to follow. 
Coordinated surveillance network (State/Central)

Joint Surveillance system (with SOP's) has to be set up for reporting active surveillance of disease both in man and animals (both at state and central levels). The network has to draft the policy for sharing data collected among organizations in real time and coordination of field activities. To facilitate this network, the existing two surveillance programs, namely, IDSP/ International Health Regulations (IHR) platform (of Human health sector) and NADRS (of Animal health sector) may link for sharing zoonotic disease. There should be provision for the data to be shared with South Asian Disease Surveillance network detailed in S1. No. 8 (Figure-1).

\section{Coordinated emergency/outbreak response (State) Central)}

To coordinate outbreak preparedness and response, involving human health and animal health sectors and conducting joint investigations by recruiting rapid response team.

\section{Coordinated research and laboratory networking (State/Central)}

To identify $\mathrm{OH}$ priority areas and develop collaborative projects to address threats at man-animal and environment interfaces. To e-connect the testing laboratories of India based on priority diseases. For best co-ordination involvement of National labs, Research centers, Regional lab, State lab, Veterinary/ Medical College, District labs is required.

\section{Coordinated capacity building and education (State) Central)}

Capacity building on disease surveillance, collaborative investigation and response will create a new cohort of experienced professionals who can effectively address $\mathrm{OH}$ challenge. This can also include development of curriculum and organization of training courses. For more complete "OH" educational identification, the resources available at www. onehealthinitiative.com are found to be a good source.

\section{Linking Indian OH platform to transnational level}

Several transnational networks have been successfully implementing $\mathrm{OH}$ approach across the globe [46]. South Asia One Health Disease Surveillance Network (SAOH-Net) is an emerging network consisting of members from governmental and nongovernmental organizations of human health, animal health, wildlife, food safety, and environment sectors from eight South Asian countries (Afghanistan, Bangladesh, Bhutan, India, Maldives, Nepal, Pakistan, and Sri Lanka) [52]. SAOH-Net was initiated in 2016 by Ending Pandemics and formally established December 2017 with support from the Ending Pandemics and Emergency Centre from Transboundary Animal Diseases of Food and Animal Organization (FAO) [56]. The Coordinated Surveillance Network of the proposed India $\mathrm{OH}$
Secretariat can be aligned with SAOH-Net for best outcomes. The country should promote and mobilize the SAOH-Net platform. For global communications, the SAOH platform should be linked to CORDS [51] (Figure-1). The country can also seek support and cooperation from international partners such as World Bank, CDC etc. to augment technical and financial resources.

\section{Organizing IHR-performance of veterinary services (PVS) national bridging workshop (NBW)}

The NBW on the IHR and the OIE's PVS pathway is a 3-day workshop which brings together many stakeholders from the animal health and the human health services of the country to improve their collaboration [57]. Many neighboring countries including Pakistan, Bangladesh, and Bhutan have conducted the NBW workshop; however, India is yet to take up this exercise. This workshop will be a useful tool for implementing $\mathrm{OH}$ as it provides an opportunity to the human and animal health services to build on the reviews of performance, gaps, and discussions for improvement conducted in their respective sectors, and to explore options for improved coordination between the sectors, to jointly strengthen their preparedness for, and control of the spread of zoonotic diseases [57].

\section{OIE-FAO-WHO Guidance}

The guidance document for the multisectoral collaboration as released jointly by OIE-FAO-WHO is (1) The Tripartite's Commitment: providing multisectoral, collaborative leadership in addressing health challenges [58] and (2) OH Approach: A Tripartite Guide to Addressing Zoonotic Diseases in Countries [59]. Both the documents are very useful for $\mathrm{OH}$ institutionalization.

\section{Conclusion}

The domain of $\mathrm{OH}$ covers joint expertise's and action toward zoonosis diagnosis, surveillance, epidemiology and control, food safety, biomedical research, environmental health, production and control of biological products, protection of drinking water, and management of Public Health emergencies and disasters. An $\mathrm{OH}$ approach guarantees healthier decisions that takes into account the consequences of development actions meant for people, animal, and nature. The recent outbreaks of highly pathogenic H5N1, KFD, Nipah, and COVID-19 invited attention to the regulatory bodies to give importance to $\mathrm{OH}$ approach for shackling emerging and re-emerging zoonosis. Considering India's geography and population size, the $\mathrm{OH}$ approach should not be restricted to control of emerging zoonosis but should also extended to foodborne hazards, AMR, biosafety issues, and environmental hazards. A useful strategy is to leverage existing programs to institutionalize the $\mathrm{OH}$ approach; wherein, the existing preparedness systems could effectively formulate the structured models for disease 
programs under the $\mathrm{OH}$ approach. The recent report of pandemics demands country to have good co-ordination between sectors and capability to uphold an effective alert system to quickly detect and respond to outbreaks and also to share information very rapidly and transparently, and solution to this is " $\mathrm{OH}$ ". Hence, let us strive to achieve $\mathrm{OH}$ for foreseeing the best harmony among man, animal, and nature.

\section{Disclosure statement}

This review compiled $\mathrm{OH}$ happenings in India based on a methodologically sound search; however, it is understood that there must have been more efforts that have not been captured through this review. As the author only screened the happenings with keywords $\mathrm{OH}$, there is always a chance that reports and articles that do not use $\mathrm{OH}$, but have relevant content might not have been included in this review. The $\mathrm{OH}$ Governance model and the $7 \mathrm{C}$ concept and views described in the article is personal and based on the author's observation and is not anyway related to policy-based decisions or the opinion of the university in which the author is working.

\section{Author's Contributions}

PN has conceptualized and drafted the manuscript, formatted it and approved the final manuscript.

\section{Acknowledgments}

The author would like to thank Kerala Veterinary and Animal Sciences University for providing a congenial environment to work on this review.

\section{Competing Interests}

The author declares that he has no competing interests.

\section{Publisher's Note}

Veterinary World (Publisher of International Journal of One Health) remains neutral with regard to jurisdictional claims in published institutional affiliation.

\section{References}

1. Bhatia, R. (2019) Implementation framework for one health approach. Indian J. Med. Res., 149(3): 329-331.

2. Vijayaraghavan, P., Balasubramanian, A. and Divyya, S. (2018) Position Paper for First One Health India Summit, Acknowledging Challenges and Paving the Way Forward. Available from: https://www.sathguru.com/news/wp-content/uploads/2018 / 05/one-health-publication may-2018. pdf. Retrieved on 05-06-2020.

3. Radhakrishnan, K.S. (2020) Importance of One Health Approach in the Time of COVID-19 Outbreak. Available from: https://www.english.manoramaonline.com/news/ columns/straight-talk/2020 / 04/08/opinion-importance-ofone-health-approach-coronavirus-outbreak.html. Retrieved on 18-06-2020.

4. Sukumaran, A. and Pradeepkumar, A.S. (2015) One health approach: A platform for intervention in emerging public health challenges of Kerala state. Int. J. One Health, 1(3): 14-25. Available from: https://www.onehealthjournal.org/ vol.1 / 3.pdf. Retrieved on 08-06-2020.

5. Carroll, D., Daszak, P., Wolfe, N.D., Gao, G.F., Morel, C.M.,
Morzaria, S., Pablos-Méndez, A., Tomori, O. and Mazet, J.A.K. (2018) The global virome project. Science, 359(6378): 872-874.

6. Department of Biotechnology, India. (2019) One Health India Conference-2019. Available from: http://www. dbtindia.gov.in/event/one-health-india-conference-2019. Retrieved on 13-06-2020.

7. Prejit, N., Sunil, B. and Vinod, V.K. (2015) ICAR Winter School on Application of One Health Concepts for Control of Emerging Zoonoses and Health Threats, Indian Agricultural Statistics Research Institute, Library Avenue, Pusa, New Delhi, India. E-Manual. Available from: https:// www.cbp.icar.gov.in/ebook22.aspx?trainingapprovedid=ws-2015-1119\& trainingtitle $=$ application $\% 20$ of $\% 20$ one $\% 20$ health $\% 20$ concepts $\% 20$ for $\% 20$ control $\% 20$ of $\% 20$ emerging\%20zoonoses\%20and\%20health\%20threats. Retrieved on 25-05-2020.

8. Varma, G.B.S. (2014) India Needs "One Health" Policy to Eradicate Zoonotic Diseases, Nature India.

9. Chatterjee, P., Kakkar, M. and Chaturvedi, S. (2016) Integrating one health in national health policies of developing countries: India's lost opportunities. Infect. Dis. Poverty, 5(1): 87.

10. Kutty, V.R. (2000) Historical analysis of the development of health care facilities in Kerala state, India. Health Policy Plan., 15(1): 103-109. Available from: https://www.semanticscholar.org/paper/historical-analysis-of-the-development-of-health-in-kutty/5b8dae77713cd5f20a98c547032fc5d0b2618b56. Retrieved on 09-06-2020.

11. Mini, M. (2020) Health Experts for One Health approach Internet. Available from: https://www.thehindu.com/news/ national/kerala/health-experts-for-one-health-approach/ article31293565.ece. Retrieved on 28-05-2020.

12. Ghosh, S. (2018) State of Forest Report Says that India's Forest and Tree Cover has Increased by 1 Percent. Available from: https:/www.india.mongabay.com/2018 / 02/state-offorest-report-says-that-indias-forest-and-tree-cover-has-increased-by-1-percent. Retrieved on 16-022018.

13. Okello, A.L. (2012) Beyond Avian Influenza: Policy Considerations for the Implementation of a One Health Approach in Developing Countries, Doctor of Philosophy University of Edinburgh. Available from: https://www.era. ed.ac.uk/bitstream/handle/1842 / 11777/okello2013.pdf?sequence $=2 \&$ isallowed $=y$. Retrieved on 14-06-2020.

14. Osburn, B., Scott, C. and Gibbs, P. (2009) One World-one medicine-one health: Emerging veterinary challenges and opportunities. Rev. Sci. Tech., 28(2): 481-486.

15. Kessler, R. and Peterson, H. (2008) Global Disease Hotspots 2.0. Available from: https://www.ecohealthalliance.org/2017 / 10/global-disease-hotspots-2-0. Retrieved on 18-06-2020.

16. Datta, S. (2019) A systematic study on the recent crisis in public health in Kerala. Asian J. Health Sci., 5(1): 5.

17. Singhal, T.A. (2020) Review of Coronavirus disease-2019 (COVID-19). Indian J. Pediatr., 87(4): 281-286.

18. White, A. and Hughes, J.M. (2019) Critical importance of a one health approach to antimicrobial resistance. Ecohealth, 16(3): 404-409.

19. Kahn, L.H. (2017) Antimicrobial resistance: A one health perspective. Trans. R. Soc. Trop. Med. Hyg., 111(6): 255-260.

20. O'Neill, J. (2016) Tackling Drug-Resistant Infections Globally: Final Report and Recommendations, Review on Antimicrobial Resistance. Available from: https://www. amr-review.org/sites/default/files/160518_final\%20paper_ with\%20cover.pdf. Retrieved on 16-06-2020.

21. van Boeckel, T.P., Brower, C., Gilbert, M., Grenfell, BT., Levin, S.A., Robinson, T.P., Teillant, A. and Laxminarayan, R. (2015) Global trends in antimicrobial use in food animals. Proc. Natl. Acad. Sci. U. S. A., 112(18): 5649-5654.

22. Sofi, S.A., Dar, M.A. and Rafiq, S. (2018) Food safety 
management of temperate fruits from farm to fork. In: Mir, S., Shah, M. and Mir, M., editors. Postharvest Biology and Technology of Temperate Fruits. Springer, Cham.

23. Lebov, J., Grieger, K., Womack, D., Zaccaro, D., Whitehead, N., Kowalcyk, B. and MacDonald, P.D.M. (2017) A framework for One Health research. One Health, 3: $44-50$

24. Robin, R.S., Vishnu, V.K., Pradipta, R., Muduli, R., Srinivasan, M. and Balasubramanian, T. (2012) Preponderance of enteric pathogens along the coastal waters of Southern Kerala, Southwest coast of India. Mar. Sci., 2(1): 6-11.

25. Palaniyandi, M., Anand, P.H. and Maniyosai, R. (2014) Spatial cognition: A geospatial analysis of vector-borne disease transmission and the environment, using remote sensing and GIS. Int. J. Mosq. Res., 1(3): 39-54.

26. Prejit (2017) One health-vision for future. In: Roy, S. and Sharma, N., editors. Veterinary Public Health: One Health. New Delhi Publishers, New Delhi.

27. Ministry of Agriculture Department of Animal Husbandry, Dairying and Fisheries. (2005) Action Plan of Animal Husbandry for Preparedness, Control and Containment of Avian Influenza. Available from: http://www.hpagrisnet. gov.in/hpagris/animalhusbandry/downloads/birdflu-actionplan-2006.pdf. Retrieved on 17-06-2020.

28. Directorate General of Health Services. (2005) Contingency Plan for Management of Human Cases of Avian Influenza. Available from: http://www.fao.org/docs/eims/ upload/221470/national_plan_ai_ind_en.pdf. Retrieved on 15-06-2020.

29. Nagarajan, S., Tosh, C., Smith, D.K., Peiris, J.S.M., Murugkar, H.V., Sridevi, R., Kumar, M., Katare, M., Jain, R., Syed, Z., Behera, P., Cheung, C.L., Khandia, R., Tripathi, S., Guan, Y. and Dubey, S.C. (2012) Avian influenza (H5N1) virus of clade 2.3.2 in domestic poultry in India. PLoS One, 7(2): e31844.

30. Wildlife Conservation Society, One World-One Health. (2004) Available from: https://www.oneworldonehealth. wcs.org/about-us/mission/the-manhattan-principles.aspx . Retrieved on 18-06-2020.

31. Mackenzie, J.S., McKinnon, M. and Jeggo, M. (2014) One health: From concept to practice. In: Confronting Emerging Zoonoses: The One Health Paradigm. Springer Japan, 2014 Available from: https://www.link.springer. com/chapter/10.1007 / 978-4-431-55120-1_8. Retrieved on 15-06-2020.

32. National Centre for Disease Control. (2020) Directorate General of Health Services, Ministry of Health and Family Welfare, Government of India. Available from: https:// www.ncdc.gov.in/index 1 .php?lang $=1 \&$ level $=1 \&$ sublink$\mathrm{id}=144 \&$ lid $=152$. Retrieved on 16-06-2020.

33. Prejit. and Jess, V. (2018) The "COHEART" Journey. Kerala Veterinary and Animal Sciences University, Kerala. Available from: http://www.coheart.ac.in/uploads/ about/1554357111.pdf. Retrieved on 18-06-2020.

34. Prejit (2018) Development of a novel course and new centre dedicated to "one health" to support the control of zoonosis and other public health needs of the country. J. Foodborne Zoonotic Dis., 6(2): 18-22.

35. Veterinary Council of India. (2019) Minimum Standards of Veterinary Education. Available from: https://www. kcvas.com/images/new\%20syllabus.pdf. Retrieved on 12-06-2020.

36. Ranjalkar, J. and Sujith, J.C. (2019) India's national action plan for antimicrobial resistance-an overview of the context, status, and way ahead. J. Family Med. Prim. Care, 8(6): 1828-1834.

37. WHO India. (2018) World Health Organization. Union Government Launches a New State-of-the Art Information Platform to Monitor Public Health Surveillance. Available from: http://www.origin.searo.who.int/india/areas/ health_systems/ihip_launch_2018/en/\#: :text=ms\%20 preeti $\% 20$ sudan $\% 2$ c $\% 20$ union $\% 20$ health,ihip $\% 20$ in $\% 20$ seven $\% 20$ states $\% 20$ today.\&text $=$ the $\% 20$ first $\% 20$ one $\% 2$ dof $\% 2$ dits, technologies $\% 20$ and $\% 20$ digital $\% 20$ health\%20initiatives. Retrieved on 16-06-2020.

38. DBT-One Health India Conference Declaration. (2019) Available from: https://www.img1.wsimg.com/blobby/ go/bdf18a05-5d66-48cb-8cad-38ee88a6d879/downloads/ ohic\%202019_declaration.pdf?ver=1556639010884. Retrieved on 18-06-2020.

39. Delhi Declaration: 2019. (2019) Available from: https:// www.who.int/docs/default-source/searo/whe/delhi-declaration-emergency-preparedness-south-east-asia-region.pdf?sfvrsn $=3293354 d$ 2. Retrieved on 15-06-2020.

40. Ahmed, S. (2019) National Institute of One Health to Come up on MAFSU Campus. Available from: https:// www.timesofindia.indiatimes.com/city/nagpur/natl-institute-of-one-health-to-come-up-on-mafsu-campus/articleshow/70899851.cms. Retrieved on 30-05-2020.

41. Kaul, R. (2020) Public Expenditure on Health to be In-Creased. Available from: https://www.hindustantimes. com/india-news/public-expenditure-on-health-to-be-increased-nirmala-sitharaman/story-dipsy19htlyycfvj031krj. $\mathrm{html}$. Retrieved on 17-05-2020.

42. DBT. (2020) Department of Biotechnology, National Expert Group on One Health. Available from: http://www.dbtindia. gov.in/sites/default/files/national\%20 expert $\% 20$ group $\% 20$ on $\% 20$ one $\% 20$ health.pdf. Retrieved on 18-06-2020.

43. Abbas, S.S., Venkataramanan, V., Pathak, G. and Kakkar, M. (2011) Rabies control initiative in Tamil Nadu, India: A test case for the 'one health' approach. Int. Health, 3(4): 231-239.

44. Schmidt, W.P., Boisson, S., Routray, P., Bell, M., Cameron, M., Torondel, B. and Clasen, T. (2016) Exposure to cows is not associated with diarrhoea or impaired child growth in rural Odisha, India: A cohort study. Epidemiol. Infect., 144(1): 53-63.

45. Koteeswaran, A. (2006) Seroprevalence of leptospirosis in man and animals in Tamilnadu. Indian J. Med. Microbiol., 24(4): 329-331.

46. Sadanandane, C., Elango, A., Marja, N., Sasidharan, P.V., Raju, K.H.K. and Jambulingam, P. (2017) An outbreak of Kyasanur forest disease in the Wayanad and Malappuram districts of Kerala, India. Ticks Tick Borne Dis., 8(1): 25-30.

47. Department of Animal Husbandry and Dairying. (2015) Bird Flu Status. Ministry of Fisheries, Animal Husbandry and Dairying. Available from: http://www.dadf.gov.in/ sites/default/filess/ai_note_updated_30.11.15.pdf01.pdf. Retrieved on 11-06-2020.

48. Arunkumar, G., Chandni, R., Mourya, D.T., Singh, S.K., Sadanandan, R., Sudan, P., Bhargava, B. and Nipah Investigators People and Health Study Group. (2019) Outbreak investigation of Nipah virus disease in Kerala, India, 2018. J. Infect. Dis., 219(12): 1867-1878.

49. National Disaster Management Authority. (2020) Government of India. Available from: https://www.ndma. gov.in/en. Retrieved on 18-06-2020.

50. Serinmary, P.R. and Prejit (2020) Emerging zoonoses and the lessons to attenuate future pandemics. J. One Health, 8(1): 19-23.

51. Vandersmissen A. and Welburn, S.C. (2014) Current initiatives in one health: Consolidating the one health global network. Rev. Sci. Tech., 33(2): 421-432.

52. Yasobanta, S., Bruchhausena, W., Saxena, D. and Falkenberga T. (2019) One health collaboration for a resilient health system in India: Learnings from global initiatives. One Health, 8: 100096.

53. Prejit. (2018) Interface Meet on "Envisioning the Institutionalization of One Health for Combating Emerging Public Health Threats in Kerala", Cochin. Available from: http://www.coheart.ac.in/download/3. Retrieved on 11-06-2020.

54. Republic of Rwanda. (2018) One Health Strategic Plan 
(2014-2018). Available from: http://www.rbc.gov.rw/fileadmin/user_upload/final_one_health_strategic_plan.pdf. Retrieved on 14-06-2020.

55. Institute of Epidemiology, Disease Control and Research. (2012) Strategic Framework for One Health Approach to Infectious Diseases in Bangladesh. Available from: http://www.iedcr.org/pdf/files/one\%20health/strategic framework_for_one_health_bangladesh-26\%20jan.pdf. Retrieved on 18-06-2020.

56. Dorjee, S., Smolinski, M., Divi, N., Kalpravidh, W. and Black, P. (2018) Establishing a One Health Disease Surveillance Network: A Recent Convergence in South Asia. Available from: https://www.cordsnetwork.org/ wp-content/uploads/2018 / 05/establishing-a-one-healthdisease-surveillance-network-a-recent-convergence-insouth-asia.pdf. Retrieved on 18-06-2020.

57. WHO Strategic Partnership for International Health
Regulations and Health Security. (2005) IHR-PVS National Bridging Workshop. Available from: https://www.extranet. who.int/sph/ihr-pvs-bridging-workshop. Retrieved on 11-06-2020.

58. Food and Agriculture Organization of the United Nations, World Organisation for Animal Health, World Health Organization. (2017) The Tripartite's Commitment: Providing Multisectoral, Collaborative Leadership in Addressing Health Challenges. Available from: https:// www.oie.int/fileadmin/home/eng/media_center/docs/pdf/ tripartite 2017.pdf. Retrieved on 18-06-2020.

59. WHO-FAO-OIE. (2019) Taking a Multisectoral, One Health Approach: A Tripartite Guide to Addressing Zoonotic Diseases in Countries. Available from: https:/www.oie.int/ fileadmin/home/eng/media_center/docs/en_tripartitezoonosesguide_webversion.pdf. Retrieved on 12-06-2020.

$* * * * * * * *$ 